\title{
Time-Temperature-Intensity-Transformation Cure Diagram for Visible Light Curable Dimethacrylate Resins
}

\author{
Jong Keun LeE, ${ }^{\dagger}$ Ju Yeol CHOI, and Bum Soon LiM* \\ Department of Polymer Science and Engineering, Kumoh National Institute of Technology, \\ 188 Shinpyung Dong, Kumi, Kyungbuk 730-701, Korea \\ *Department of Dental Biomaterials, College of Dentistry and Intellectual Biointerface Engineering \\ Research Center, Seoul National University, Seoul 110-749, Korea
}

(Received April 23, 2003; Accepted July 30, 2003)

\begin{abstract}
The cure behavior of two dimethacrylate resin formulations activated by visible light $(\lambda=400-500 \mathrm{~nm})$ was investigated by means of a rapid monitoring dynamic mechanical technique. Storage modulus $(G)$ and $\tan \delta v s$. time data were obtained for different light intensities $\left(20-600 \mathrm{~m} \mathrm{~W} \mathrm{~cm}^{-2}\right)$ and cure temperatures $\left(25-60{ }^{\circ} \mathrm{C}\right)$. Gelation and vitrification time were estimated from initial rise of $G^{\prime}$ and maximum peak of $\tan \delta v s$. time curve, respectively, and used to construct time-temperature-intensity-transformation (TTIT) cure diagram. Physical states of material in the regions divided by the estimates of the transforming times were incorporated in the cure diagram. It was found that the dimethacrylate systems undergo phase transformation initially from liquid to rubber and finally to glass. Effects of intensity and temperature on the gelation and vitrification are discussed and compared for the two formulations.

KEY WORDS Time-Temperature-Intensity-Transformation (TTIT) Cure Diagram / Dynamic Mechanical Analysis / Visible Light / Dimethacrylate /
\end{abstract}

Visible light curable dimethacrylate resins are widely used as an important base material for dental restorative composites as a consequence of their advantages such as the short application time and the aesthetic performance in clinical applications. However, there remain many issues of the dimethacrylate based dental resins. Rapid reaction of the light curing systems leads to incomplete cure, ${ }^{1-5}$ reducing the mechanical strength and increasing the swelling of the material. Unreacted monomers trapped in the incompletely cured material could be extractable, causing various troubles in the body. ${ }^{6-9}$ Shrinkage during photo-polymerization is also one of principal drawbacks in practical applications. ${ }^{10,11}$

Since final properties after cure are closely related to the details of cure process, understanding cure process could be especially significant to improve performance qualities in network forming systems. During forming network, extreme changes take place not only molecularly from monomers to highly crosslinked polymer but also macroscopically (rheologically) from the fluid state prior to gelation to the glassy state after vitrification. Dramatic rheological changes during the network formation are considered to be of great importance in characterizing and understanding the cure process. Useful information for ultimate final properties and performance of material can be obtained from the rheological study during the changes.

Dynamic mechanical analysis (DMA) is a versatile technique that may be used to simultaneously characterize both rheological and thermal properties of a wide range of sample types. ${ }^{12}$ Dynamic mechanical properties of the material are evaluated by either applying a small oscillating strain to the sample and measuring the resulting stress or by applying a periodic stress and measuring the strain. The quantitative properties measured under the controlled mechanical oscillation include storage modulus $\left(G^{\prime}\right)$ and loss modulus $\left(G^{\prime \prime}\right)$. The storage modulus relates to the energy storing quality and is equivalent to the Young's modulus of an elastic solid, and the loss modulus to the dissipative and viscous component of the material. The ratio of loss $\left(G^{\prime \prime}\right)$ to storage modulus $\left(G^{\prime}\right)$ is referred to as the mechanical damping $(\tan \delta)$.

One of achievements of dynamic mechanical studies in thermosetting resins is the time-temperaturetransformation (TTT) cure diagram from the work of Gillham and Enns. ${ }^{13-15}$ The TTT cure diagram, established by means of a freely oscillating DMA techniqueTorsional Braid Analysis (TBA), is recognized as a basis for analyzing and designing cure processes, describing the various physical states of a thermosetting material during isothermal cure reaction. The cure process was characterized by the resin rheology as a function of time and temperature based on the two phenomena of critical importance; gelation and vitrification.

As for the thermosetting materials, it is essential to investigate the cure behavior of photoinitiated systems.

${ }^{\dagger}$ To whom correspondence should be addressed (E-mail: jklee@kumoh.ac.kr). 
The cure behavior has been mainly studied by measuring degree of conversion using differential scanning calorimetry (DSC) $)^{5,16}$ and fourier transform infrared spectrometry (FT-IR $)^{2,3}$ for visible light activated resin composites. Recently, dynamic mechanical analysis (DMA) has been used to estimate storage modulus development during irradiation. ${ }^{17}$ In this study, we intend to employ a DMA technique, which is capable of in-situ monitoring rheological properties during cure, and develop time-temperature-intensity-transformation (TTIT) cure diagram for two different dimethylacrylate resins activated by visible light. The cure diagram can be used to track the effect of light intensity on the physical state of the network forming material coupled with cure time and temperature in photoinitiated systems.

\section{EXPERIMENTAL}

The two formulations were prepared from UDMA (1,6-bis(methacrylyloxy-2-ethoxycabonylamino)-2,4, 4-trimethylhexane, Esstech, USA) or Bis-GMA (2, 2-bis[4-(2-hydroxy-3-methacrylyloxypropoxy)phenyl] propane, Esstech, USA) as a base resin. The resin was mechanically blended with a TEGDMA (triethylene glycol dimethacylate, Esstech, USA) diluent at room temperature for $30 \mathrm{~min}$. The mixtures were subsequently stirred for additional $120 \mathrm{~min}$ at room temperature for UDMA and $600 \mathrm{~min}$ at $35^{\circ} \mathrm{C}$ for Bis-GMA after adding a CQ (di-camphorquinone, Polysciences, USA) catalyst, a DMAEMA (2(dimethylamino)ethyl methacrylate, Aldrich, USA) co-catalyst, and a BHT (butylated hydroxytolune, Sigma, USA) inhibitor. Bis-GMA was mixed for a longer time at a higher temperature due to its higher viscosity than UDMA. The composition of the sample mixtures used in this study is $69.23 \mathrm{wt} \%$ of UDMA or Bis-GMA, $29.67 \mathrm{wt} \%$ of TEGDMA, $0.7 \mathrm{wt} \%$ of CQ, $0.35 \mathrm{wt} \%$ of DMAEMA, and $0.05 \%$ of BHT. Note that these compositions are one of typical resin formulations using in restorative dental composites. Chemical structures of the components are represented in Figure 1. For the dimethacrylate systems used in this experiment, photocuring is mainly based on the free-radicals formed by visible light in the reaction with amines. ${ }^{18}$

\section{Dynamic Mechanical Analysis}

In photoinitiated systems, network structure develops very rapidly with big rheological changes, ranging from low-viscous liquid to gel and eventually to hard solid as cure reaction proceeds. In the fast reacting cure systems, fast data acquisition rate is critical in order to follow the rheological transformations ac- curately. In a classical DMA technique, data analysis requires the machine to collect data over at least one complete period of oscillation. Therefore, the fastest data acquisition rate would be equal to the frequency in $\mathrm{Hz}$ theoretically. A dynamic mechanical analysis technique (StressTech Rheometer, Reologica Instrument, Sweden) used in this experiment is capable of collecting the rheological data more than 50 points s$^{-1}$. In this study, data acquisition rate was 5 points $\mathrm{s}^{-1}$.

Another important factor may be the way of irradiation to the sample. Figure 2 shows a schematic drawing of the sample holder. Two parallel plates of a stationary quartz disc plate $(\phi=30 \mathrm{~mm}$, thickness $=3.2 \mathrm{~mm})$ and an oscillatory upper plate $(\phi=8 \mathrm{~mm})$ are designed to accommodate a liquid sample. After approximately $50 \mathrm{mg}$ of sample was placed on the quartz plate, the upper rod was slowly moved down to the sample until preassigned gap distance reaches. Then oscillation was imposed to the sample with frequency of $1 \mathrm{~Hz}$ under applied stress of $8000 \mathrm{~Pa}$. Gap between the plates (or sample thickness) was initially fixed to be $0.6 \mathrm{~mm}$, but was reduced during curing due to the cure shrinkage.

Cure was induced by irradiating visible light $(\lambda=$ 400-500 nm, Variable Intensity Polymerizer, Bisco Inc., USA) through the quartz disc from bottom as shown in Figure 2. Gap between the quartz disc and the tip of light source was $0.5 \mathrm{~mm}$. Note that the spot diameter of the irradiation from the light source is $11 \mathrm{~mm}$, which is enough to irradiate homogeneously throughout the sample. After an initial period of $10 \mathrm{~s}$ for stabilization, data were collected for $70 \mathrm{~s}$ as soon as the light was turned on. Lamp was on for $30 \mathrm{~s}$ under the intensities of 20,70, 120,300, and $600 \mathrm{~mW} \mathrm{~cm}^{-2}$. Cure temperatures were 25,37 (body temperature), 50, and $60{ }^{\circ} \mathrm{C}$. Note that the irradiation time of $30 \mathrm{~s}$ and the ranges of light intensity are based on the conditions in clinical applications of dental restorative composites. For the cure temperature, a visible light curable dental restorative composite is normally prepared at room temperature and can be warmed up to over $60^{\circ} \mathrm{C}$ under certain circumstances (drinking hot water or tea, etc.) after restorative treatment. Each test was performed after checking the light intensity by means of a radiometer (Demetron Research Co., USA). Transmitted intensity through the sample on the quartz plate was also checked by the radiometer if there is any reduction of light due to the sample. No reduction of intensity for all samples was observed, indicating that the same amount of intensity is applied through the sample depth.

\section{RESULTS}

Storage modulus $\left(G^{\prime}\right)$ and $\tan \delta\left(G^{\prime \prime} / G^{\prime}\right)$ were mea- 
<smiles>C=C(C)C(=O)OCCCOC(=O)NCC(C)(C)CC(C)CCNC(=O)OCCC(=O)OC(C)(C)C</smiles>

UDMA

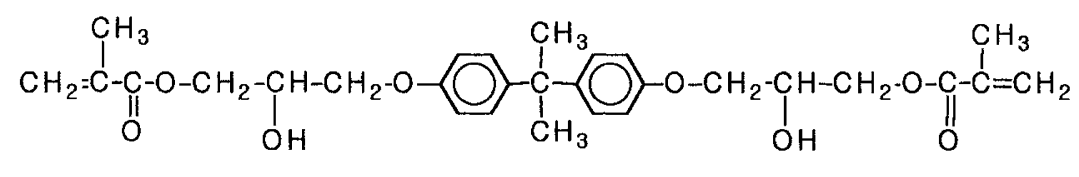

Bis-GMA

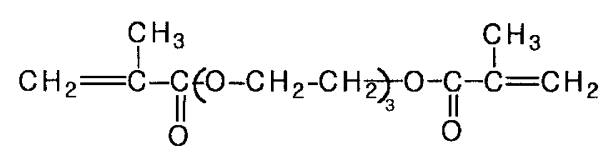

TEGDMA

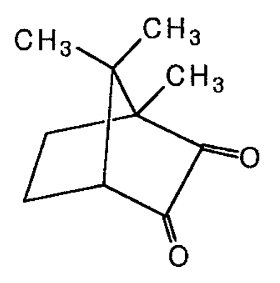

$C Q$<smiles>C=C(C)C(=O)OCCN(C)C</smiles>

\section{DMAEMA}

Figure 1. Chemical structures of the formulations used in this study.

sured as a function of time at different intensities and temperatures for UDMA and Bis-GMA based formulations. In Figures 3 and 4, representative $G$ and tan $\delta v s$. time curves for different intensities at $37^{\circ} \mathrm{C}$ and for different temperatures at $300 \mathrm{~mW} \mathrm{~cm}^{-2}$ are plotted for UDMA, respectively. The same data for Bis-GMA are shown in Figures 5 and 6, respectively. For clarity, the curves have been displaced vertically by arbitrary amounts, and intensity and temperature values are indicated on the corresponding curves. Also indicated in the figures is the irradiation period (i.e., $30 \mathrm{~s}$ ). Looking at the $G^{\prime}$ and $\tan \delta$ curves obtained in this experiment, the DMA machine is good enough for tracking the rapidly changing rheological properties.

As shown in Figures 3 and 5, the storage modulus was initially maintained almost constant after light is on, followed by rising rapidly and leveling off thereafter. The same trends were exhibited at all intensities and temperatures for both samples. The modulus curve shifts to a shorter time scale and the rising slope becomes stiffer with increasing intensity and temperature. Corresponding $\tan \delta$ curves in Figures 4 and 6 show a distinct peak which shifts to a shorter time scale and becomes sharper with increase of intensity and temperature. In the beginning of the experiment, there is scattering in $\tan \delta$ data as shown in the figures. This may be due to the big amplitude of oscillation at the applied stress of $8000 \mathrm{~Pa}$ in a liquid state of sample. However, it does not disturb the $\tan \delta$ peak appearing afterward. 


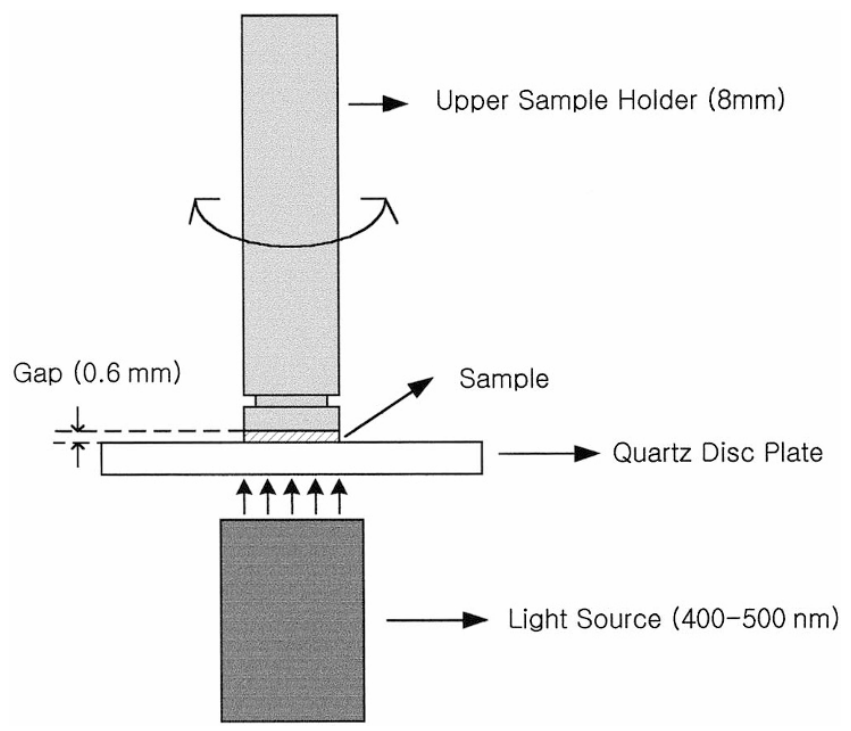

Figure 2. Schematic diagram of a sample holder.

\section{G' vs. Time for UDMA}

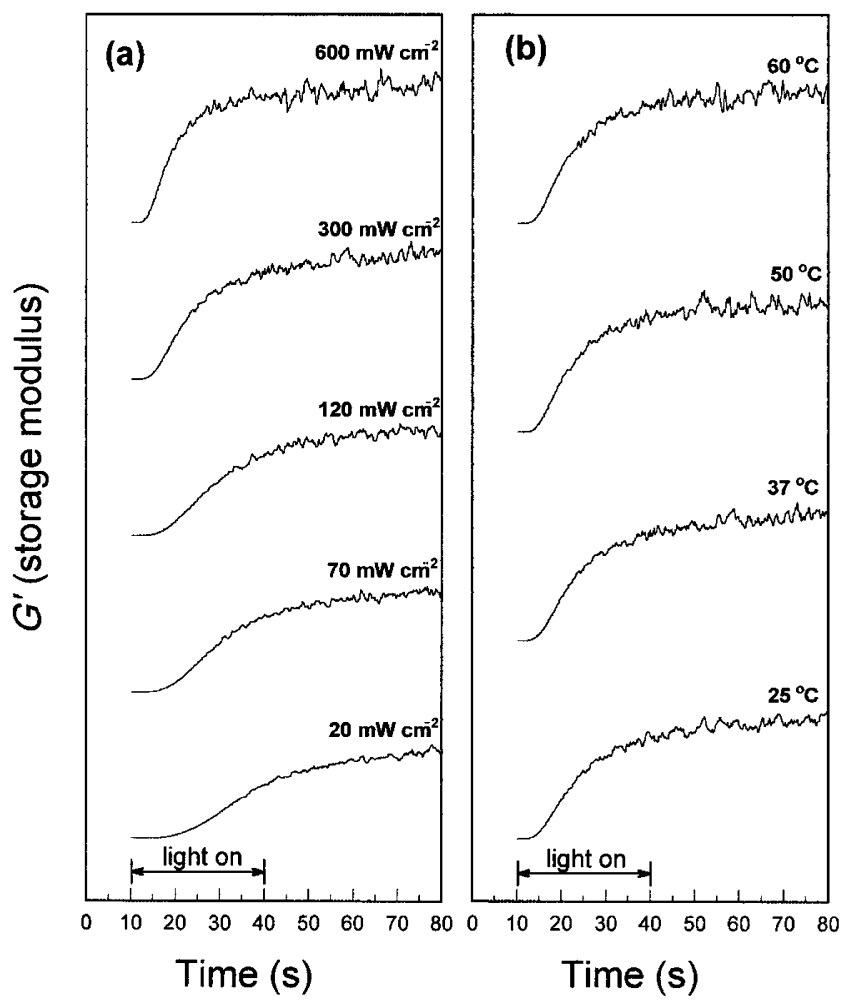

Figure 3. Storage modulus $\left(G^{\prime}\right)$ vs. time curves (a) for different intensities at $37^{\circ} \mathrm{C}$ and (b) for different temperatures at $300 \mathrm{~mW} \mathrm{~cm}^{-2}$ for a UDMA system.

\section{DISCUSSION}

In the case of thermosetting systems, the cure parameters controlling processing and properties are time and temperature. Time positions of the two macroscopic phenomena, gelation and vitrification, were an important basis for developing the TTT cure diagram
Tan $\delta$ vs. time for UDMA

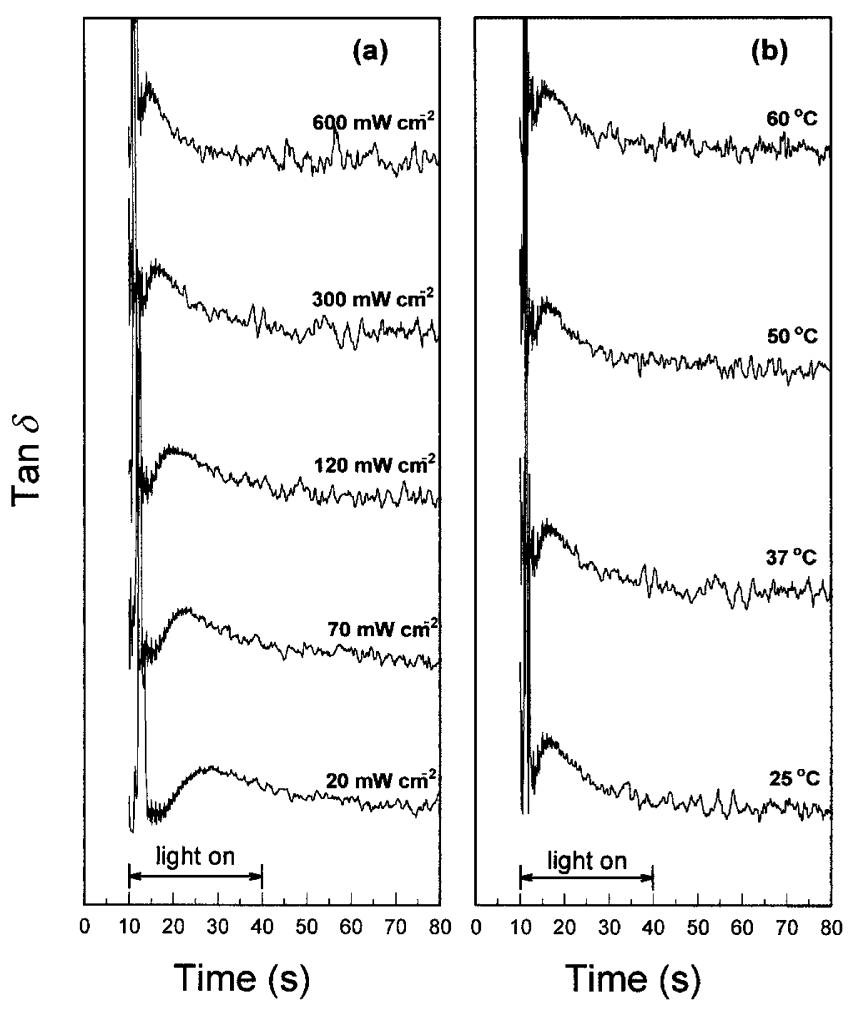

Figure 4. Tan $\delta$ vs. time curves (a) for different intensities at $37^{\circ} \mathrm{C}$ and (b) for different temperatures at $300 \mathrm{~mW} \mathrm{~cm}^{-2}$ for a UDMA system.

in thermosets. Gelation defined molecularly by incipient formation of network during cure reaction can be measured from the major changes in rheological properties (e.g., viscosity) and mechanical properties (e.g., modulus) at a macroscopic level. There are various ways to assign the location of gel point macroscopically. Dynamic parallel plate rheometry has been used to determine the gel point at which viscosity increases abruptly. ${ }^{19-21}$ TBA experiments showed that gelation can be assigned to the first loss damping peak ${ }^{13-15}$ which is reported to be actually attributed to isoviscous state. $^{22}$ Since the elasticity of the forming network begins to build at the gel point, the macroscopic gelation has been taken as onset of the initial increase in modulus measured by DMA. ${ }^{20,23}$ Vitrification is known to be a glass forming process as a result of reaching the glass transition temperature of the reacting system to isothermal temperature of cure. The vitrification is readily identified as a loss peak from DMA that accompanies a large increase in modulus during cure.

Construction of Time-Temperature-Intensity-Transformation (TTIT) Cure Diagram

Dynamic mechanical measurements were made in a wide range of intensity and temperature as a func- 
$G^{\prime}$ vs. time for Bis-GMA

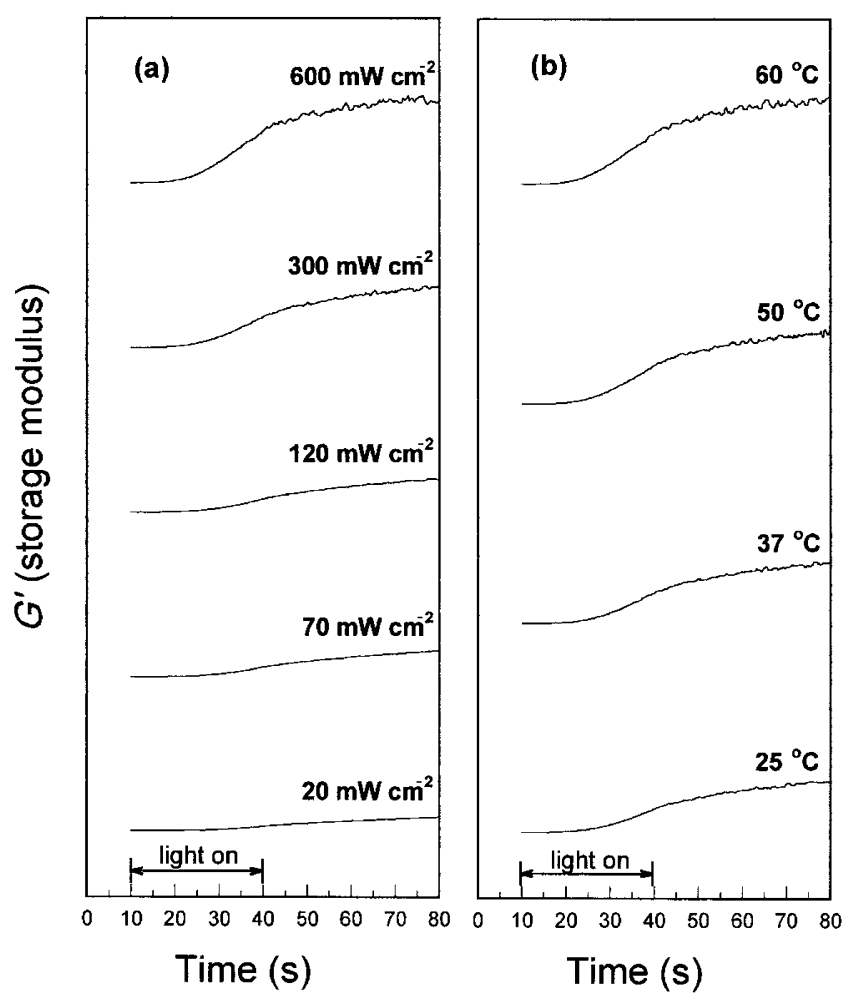

Figure 5. Storage modulus $\left(G^{\prime}\right)$ vs. time curves (a) for different intensities at $37{ }^{\circ} \mathrm{C}$ and (b) for different temperatures at $300 \mathrm{~mW} \mathrm{~cm}^{-2}$ for a Bis-GMA system.

tion of time and the results were used to build timetemperature-intensity-transformation (TTIT) cure diagram in this study. Time to gelation $\left(t_{\text {gel }}\right)$ was determined from the onset of increase in storage modulus from a series of the storage modulus $(G) v s$. time curves for UDMA and Bis-GMA sample. This is equivalent to the onset of elasticity from a definition of gelation. ${ }^{20,23}$ A distinct peak on the tan $\delta$ curve is considered to be due to vitrification. Time to vitrification $\left(t_{\mathrm{vit}}\right)$ was taken from the maximum $\tan \delta$ peak position. Based on the $t_{\text {gel }}$ and $t_{\mathrm{vit}}$, TTIT cure diagrams for UDMA and Bis-GMA are constructed in threedimensional space and shown in Figures $7 \mathrm{a}$ and $7 \mathrm{~b}$, respectively.

The two time positions in the diagram lead to the three dimensional space to be divided into three different regions; before $t_{\mathrm{gel}}$, between $t_{\mathrm{gel}}$ and $t_{\mathrm{vit}}$, and after $t_{\mathrm{vit}}$. In order to identify the physical state of each region, specimens were cured at $300 \mathrm{~mW} \mathrm{~cm}^{-2}$ and $25^{\circ} \mathrm{C}$ in the DMA machine for different periods of time; 2 and $3 \mathrm{~s}$ (i.e., before $\left.t_{\mathrm{gel}}\right), 3.5$ and $7.5 \mathrm{~s}$ (i.e., between $t_{\mathrm{gel}}$ and $t_{\mathrm{vit}}$ ), and 10 and $25 \mathrm{~s}$ (i.e., after $t_{\mathrm{vit}}$ ) for UDMA and Bis-GMA, respectively. The cure times were selected from the TTIT cure diagram obtained in this study. Solubility of the cured specimen were examined in ace-
Tan $\delta$ vs. time for Bis-GMA

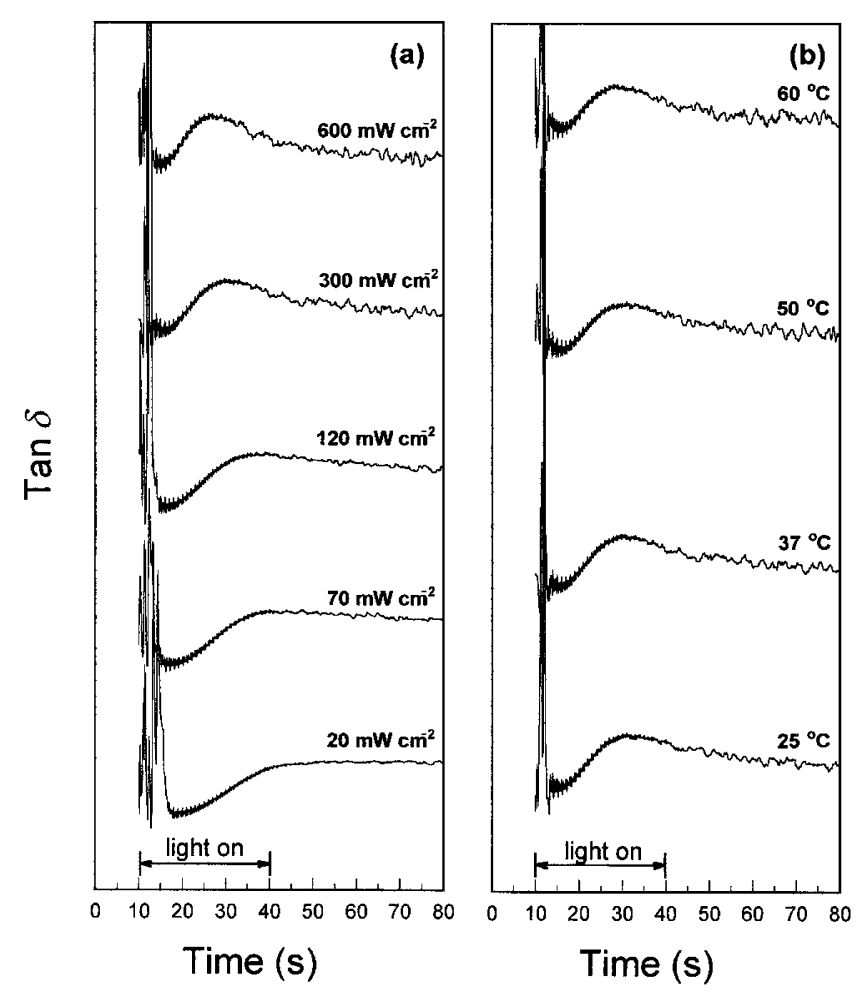

Figure 6. Tan $\delta v s$. time curves (a) for different intensities at $37^{\circ} \mathrm{C}$ and (b) for different temperatures at $300 \mathrm{~mW} \mathrm{~cm}^{-2}$ for a BisGMA system.

tone. All the specimens were completely dissolved before $t_{\mathrm{gel}}$. However, between $t_{\mathrm{gel}}$ and $t_{\mathrm{vit}}$, specimens were swelled a little $(\sim 5 \%$ increase in weight after $2 \mathrm{~h}$ of immersion in acetone) without dissolution. Almost no swelling was observed after $t_{\text {gel }}$. The cured specimens were also examined by bending manually. Specimens between $t_{\text {gel }}$ and $t_{\mathrm{vit}}$ were very flexible without breaking, but those after $t_{\text {vit }}$ became brittle with breaking into pieces. From the tests above, the state of phase of the each region in the diagram was assigned to be liquid before $t_{\mathrm{gel}}$, rubber between $t_{\mathrm{gel}}$ and $t_{\mathrm{vit}}$, and glass after $t_{\text {vit }}$. The physical states were incorporated in the cure diagrams as shown in Figures $7 \mathrm{a}$ and $7 \mathrm{~b}$. All the tests should be made immediately after cure at each phase region because of the fast property changes due to postcure. As shown in Figures 3 and 5, the storage modulus increases quite rapidly before reaching to level-off time after gelation.

\section{Effects of Light Intensity and Cure Temperature}

Intensity and temperature affects differently on gelation and vitrification in this study. From the cure diagram constructed, gelation and vitrification time were taken at the lowest $\left(C_{\mathrm{L}}=20 \mathrm{~mW} \mathrm{~cm}^{-2} \times 25^{\circ} \mathrm{C}\right.$, marked by $a$ for gelation and $c$ for vitrification in Figures $7 \mathrm{a}$ 
TTIT Cure Diagram for UDMA

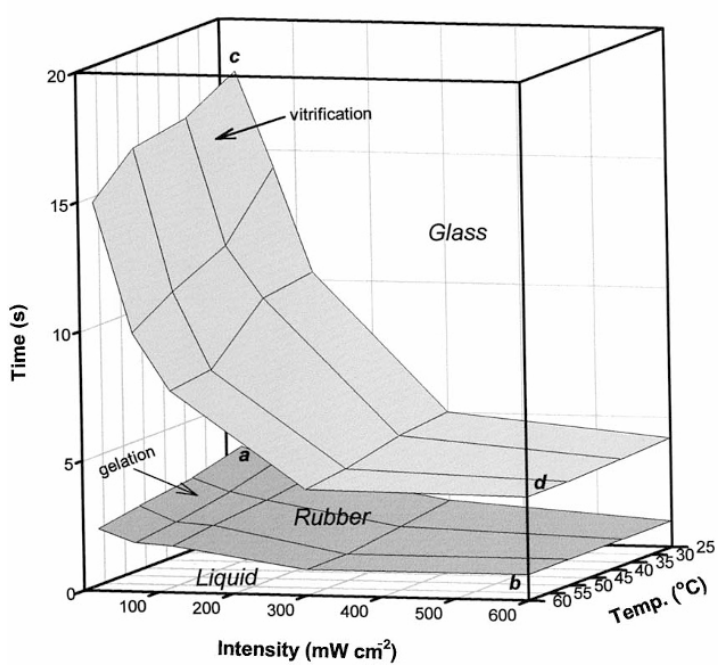

(a)

TTIT Cure Diagram for Bis-GMA

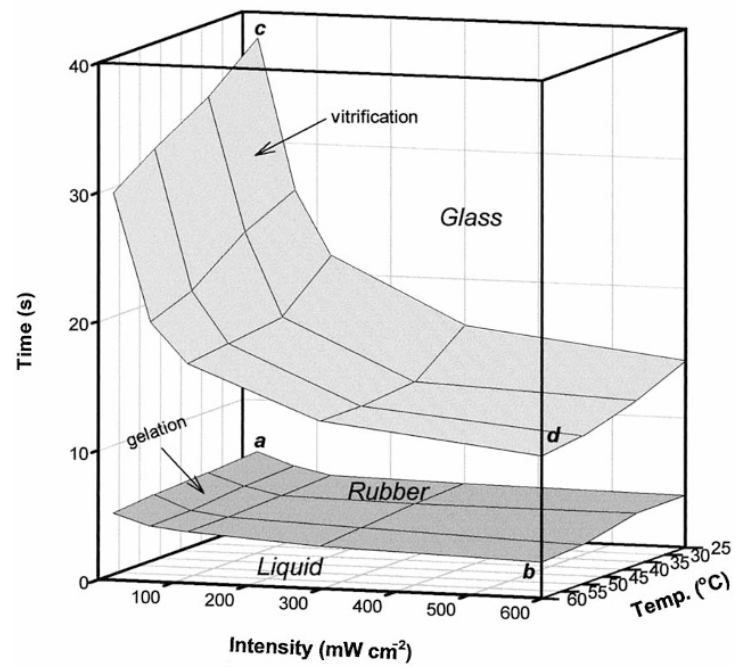

(b)

Figure 7. Time-temperature-intensity-transformation (TTIT) cure diagram (a) for a UDMA and (b) for a Bis-GMA system.

and $7 \mathrm{~b})$ and the highest intensity and temperature $\left(C_{\mathrm{H}}=\right.$ $600 \mathrm{~mW} \mathrm{~cm}^{-2} \times 60{ }^{\circ} \mathrm{C}$, marked by $b$ for gelation and $d$ for vitrification in the same figures), where cure reaction is considered to be the slowest and the fastest, respectively. For UDMA, the transformation times shift to a shorter time; gelation from $3.5 \mathrm{~s}$ at $C_{\mathrm{L}}$ (point $a$ ) to $1 \mathrm{~s}$ at $C_{\mathrm{H}}$ (point $b$ ) and vitrification from $18 \mathrm{~s}$ at $C_{\mathrm{L}}$ (point $c$ ) to $4 \mathrm{~s}$ at $C_{\mathrm{H}}$ (point $d$ ). In the case of Bis-GMA, gelation shifts from $6 \mathrm{~s}$ at $C_{\mathrm{L}}$ (point $a$ ) to $2.8 \mathrm{~s}$ at $C_{\mathrm{H}}$ (point $b$ ) and vitrification from $38 \mathrm{~s}$ at $C_{\mathrm{L}}$ (point $c$ ) to $11 \mathrm{~s}$ at $C_{\mathrm{H}}$ (point $d$ ). Amounts of shift under the two different conditions for gelation are only $2.5 \mathrm{~s}$ for UDMA and $3.2 \mathrm{~s}$ for Bis-GMA by increasing from $C_{\mathrm{L}}$ to $C_{\mathrm{H}}$, but those for vitrification are $14 \mathrm{~s}$ for UDMA and $27 \mathrm{~s}$ for Bis-GMA. Therefore, a main cure parameter in photoinitiated systems is found to be light intensity rather than cure temperature. Also vitrification is greatly affected by the light, especially at a lower intensity range up to $300 \mathrm{~mW} \mathrm{~cm}^{-2}$ for both systems. The effect of intensity becomes larger at lower temperatures.

At all light intensities and cure temperatures, uncured sample undergoes transformation from liquid to rubber and finally to glass for different periods of time depending on intensity and temperature. The TTIT cure diagram for Bis-GMA exhibits similar trend but transforming times are much longer compared to that for UDMA, indicating that cure reaction proceeds much slowly in a Bis-GMA system. Bis-GMA has more rigid molecular structure due to the phenylene rings as seen in Figure 1, showing the higher viscosity compared to UDMA. The slower cure rate in Bis-GMA is also related to the rigidity of chain structure, restricting the mobility of functional groups for further reaction to build up network.

The TTIT cure diagram in this study is useful as a basic framework for understanding and predicting of cure process and kinetics in photoinitiated systems. This diagram can also provide a practical guide to determine proper cure parameters for controlling final properties and to solve the drawbacks in photoinitiated systems. For instance, a major issue in dental composites is volume shrinkage associated with polymerization, which leads to marginal discontinuity and contraction stresses in adhesive restorations. One of approaches to minimize the polymerization shrinkage is a two-step cure process; pre-polymerization at low light intensity followed by final cure at high light intensity. ${ }^{24,25}$ Information on the physical state at a particular light intensity, cure time, and cure temperature after the first irradiation at low light intensity should be known for more effective irradiation conditions.

\section{CONCLUSION}

For the two visible light curable samples based on dimethacrylate resins, UDMA and Bis-GMA, rheological properties, storage modulus and corresponding tan $\delta$ values, were obtained as a function of time by means of a fast monitoring dynamic mechanical technique. Using the gelation and vitrification times determined from the storage and $\tan \delta$ data $v s$. time curves, timetemperature-intensity-transformation (TTIT) cure diagram was successfully constructed for both samples. The physical state of phase during curing was indicated in the diagram. It was found that sample undergoes transformation initially from liquid to rubber (gelation) and finally to glass (vitrification) during cure. 
The transforming times were shifted to a shorter time with increase of intensity and temperature, meaning that cure advances more rapidly. Vitrification is greatly influenced by the intensity of light at a lower intensity range compared to gelation. The effects of intensity and temperature on gelation and vitrification are similar for both samples, but cure reaction rate is much slower in a Bis-GMA system with more rigid chain structure.

Acknowledgment. This work was supported by Korea Research Foundation Grant (KRF-2001-002E00240). Authors would like to acknowledge Esstech company for generous supply of monomers.

\section{REFERENCES}

1. I. E. Ruyter and H. Oysaed, Acta Odontol. Scand., 40, 179 (1982).

2. G. C. Eliades, G. J. Vougiouklakis, and A. A. Caputo, Dent. Mater., 3, 19 (1987).

3. K. Chung and E. H. Greener, J. Oral. Rehabil., 15, 555 (1988).

4. S. Imazato, J. F. McCabe, H. Tarumi, A. Ehara, and S. Ebisu, Dent. Mater., 17, 178 (2001).

5. J. M. Antonucci and E. E. Toth, J. Dent. Res., 62, 121 (1983).

6. T. M. Gerzina and W. R. Hume, J. Oral. Rehabil., 21, 463 (1994).

7. C. Hansel, G. Leyhausen, U. E. Mai, and W. Geurtsen, Dent. Mater., 77, 60 (1998).

8. W. Spahl, H. Budzikiewicz, and W. Geurtsen, J. Dent. Res.,
73 (spec Iss), 297 (1994).

9. M. Taira, A. M. Khan, K. Ohmato, N. Satou, H. Shintani, and K. Wakasa, J. Mater. Sci. Lett., 13, 1229 (1994).

10. R. Labella, P. Lambrechts, B. Van Meerbeek, and G. Vanherle, Dent. Mater., 15, 128 (1999).

11. N. Silikas, G. Eliades, and D. C. Watts, Dent. Mater, 16, 292 (2000).

12. K. P. Menard, "Dynamic Mechanical Analysis: A Practical Introduction”, CRC Press, Boca Raton, FL, 1999.

13. J. B. Enns and J. K. Gillham, J. Appl. Polym. Sci., 28, 2567 (1983).

14. J. B. Enns and J. K. Gillham, Adv. Chem. Ser., 203, 27 (1983).

15. J. K. Gillham, Polym. Eng. Sci., 26, 1429 (1986).

16. A. Maffezzoli, R. Terzi, and L. Nicolais, J. Mater. Sci., Mater. Med., 6, 155 (1995).

17. R. L. Sakaguchi, N. C. Shah, B. S. Lim, J. L. Ferracane, and S. E. Borgersen, Dent. Mater., 18, 197 (2002).

18. L.-A. Linden, in "Radiation Curing in Polymer Science and Technology", J. P. Fouassier and J. F. Rabek, Eds., Elsevier Science Inc., New York, N.Y., 1993, p 387.

19. H. H. Winter, Polym. Eng. Sci., 27, 1698 (1987).

20. M. Feve, Makromol. Chem., Macromol. Symp., 30, 95 (1989).

21. A. C. Senhaji and D. Harran, Makromol. Chem., Macromol. Symp., 30, 109 (1989).

22. H. Stutz and J. Mertes, J. Appl. Polym. Sci., 38, 781 (1989).

23. R. B. Prime, J. M. Burns, M. L. Karmin, C. H. Moy, and H.-B. Tu, J. Coat. Technol., 60, 55 (1988).

24. D. C. Watts and A. A. Hindi, Dent. Mater, 15, 39 (1999).

25. B. S. Lim, J. L. Ferracane, R. L. Sakaguchi, and J. R. Condon, Dent. Mater, 18, 436 (2002). 